\title{
Fenologia e produção de cultivares de amoreira-preta em sistema agroecológico
}

\author{
Phenology and production of blackberry cultivars in agroecological system
}

\author{
Luis Eduardo Corrêa Antunes ${ }^{\mathrm{I}}$ Emerson Dias Gonçalves ${ }^{\mathrm{II}}$ Renato Trevisan ${ }^{\mathrm{III}}$
}

\section{RESUMO}

A amoreira-preta é uma espécie de exploração recente no Brasil. Nos últimos ano, s tem sido dada especial atenção ao cultivo orgânico ou agroecológico dessa espécie. o objetivo deste trabalho foi verificar o comportamento fenológico e produtivo das cultivares de amora-preta 'Tupy', 'Guarani', 'Caingangue', 'Cherokee' e 'Brazos', e das seleções denominadas 'seleção 97' e 'seleção 787' na região de Pelotas, Rio Grande do Sul(RS), em sistema agroecológico. O trabalho foi realizado na Estação Experimental de Cascata (EEC), Embrapa Clima Temperado. As plantas foram dispostas no pomar, em blocos varietais aleatórios, com 10 plantas por genótipo, perfazendo quatro linhas com duas cultivares por linha. Foram observadas as datas de início da floração e fim da floração, início e final de colheita, massa (gramas) e número de frutos por planta, teor de sólidos solúveis totais ( ${ }^{\circ}$ Brix), produção média por planta $\left(\mathrm{g} \mathrm{pl}^{-1}\right)$ e produtividade estimada por hectare $\left(\mathrm{kg} \mathrm{ha}^{-1}\right)$. Para análise das características dos frutos, a média de cada ano de avaliação (três) foi considerada como uma repetição. Na região de Pelotas-RS, é viável o cultivo agroecológico de amoreira-preta. Não há diferenças de produção, produtividade, número de frutos e teores de sólidos solúveis totais entre os genótipos estudados.

Palavras-chave: Rubus, produtividade, qualidade.

\section{ABSTRACT}

The aim of this research was to evaluate yield and quality of blackberry cultivars Tupy, Guarani, Caingangue, Cherokee and Brazos, and the 'selection 97' and 'selection 787' at Pelotas, in the Southern of Rio Grande do Sul State, under agroecological system. The plants were available in blocks varietal randomized in the orchard, with 10 plants per row, four lines with two cultivars per line. For statistic analysis of the fruit characteristics each year of evaluation (three) was considered as one repetition. The characteristics evaluate were the beginning and end of flowering and harvest, mass ( $g$ ), number of fruit per plant, content of total soluble solids ( ${ }^{\circ}$ Brix),

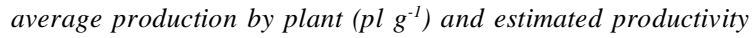
per hectare $\left(\mathrm{ha}^{-1} \mathrm{l}^{-1}\right.$ ). In the Pelotas-RS region there is technical viability for blackberry growing at agroecological system. There was no difference between cultivars evaluated for yield, fruit number and total soluble solids content.

Key words: Rubus, productivity, fruit quality.

\section{INTRODUÇÃO}

Sistemas de produção agrícola, além de processos ecológicos, envolvem também processos sociais, sendo a agricultura o resultado da coevolução de sistemas naturais e sociais. É com esse entendimento que a agroecologia, na busca de agroecossistemas sustentáveis, procura estabelecer a base científica para uma agricultura que tenha como princípios básicos a menor dependência possível de insumos externos à unidade de produção agrícola e a conservação dos recursos naturais (AQUINO \& ASSIS, 2007).

Uma das opções de cultivo para o sistema de produção agroecológica é a amoreira-preta, devido principalmente a sua rusticidade de cultivo, ao alto rendimento (ATTILIO, et al., 2009) e ao valor agregado

IEmbrapa Clima Temperado, CP 403, 96001-970, Pelotas, RS, Brasil. E-mail: luis.eduardo@cpact.embrapa.br. Autor para correspondência.

"Epamig, Fazenda Experimental de Maria da Fé, Bairro Vargedo, Maria da Fé, MG, Brasil.

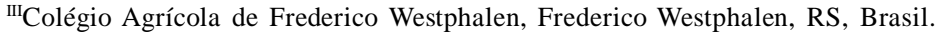


(ANTUNES, 2002). Segundo STRIK et al. (2007), de 1995 a 2005 houve um aumento de $45 \%$ na área plantada no mundo com amoreira-preta, chegando a 20.035ha. Para CLARK (2006), nesse mesmo período, a produção de amora-preta e o interesse na cultura foram os maiores de todos os tempos, com aumentos significativos de produção para o mercado de frutas frescas nos últimos anos.

Em relação à América do Sul, em 2005, existiam 1.597ha cultivados, com uma produção de 6.380 toneladas. O Chile contava com $450 \mathrm{ha}$, em 2005 , com uma produção total de 3.879 toneladas e essa área plantada aumentou 50\% de 1995 a 2005. No Brasil, existem 250ha plantados, com uma produção de 780 toneladas, das quais cerca de $15 \%$ são exportadas, sendo plantada principalmente a cultivar 'Tupy'. A maior parte da produção é processada e utilizada para consumo no mercado interno (STRIK et al., 2007).

Em relação ao sistema de produção, verificase que, no cultivo convencional, a produtividade da amoreira-preta pode ser superior a 10 toneladas por hectare (ANTUNES, 2002; ANTUNES \& RASEIRA, 2007). Já BROETTO et al., (2009) obtiveram, em cultivo orgânico, três toneladas por hectare com a cultivar 'Xavante', em Guarapuava, no Paraná(PR).

Diante do exposto, o objetivo deste trabalho foi avaliar a fenologia e produção de frutos de sete genótipos de amoreira-preta em sistema agroecológico, na região de Pelotas, Rio Grande do Sul (RS).

\section{MATERIAL E MÉTODOS}

O trabalho foi realizado no campo experimental da Estação Experimental da Cascata (EEC), Embrapa Clima Temperado (Latitude 31 ${ }^{\circ} 37^{\prime} 15,57^{\prime \prime} \mathrm{S}$; Longitude 52 31' 30,77”; Altitude de 164 metros). As avaliações foram realizadas por três safras consecutivas: ciclo produtivo 2003/04, 2004/05 e 2005/ 06, com cinco cultivares de amoreira-preta ('Tupy', 'Guarani', 'Caingangue', 'Cherokee'e 'Brazos') e duas seleções ('seleção 97' e 'seleção 787') do programa de melhoramento genético da Embrapa.

Os genótipos foram plantados em julho de 2000 , em espaçamento de $0,7 \times 3,5 \mathrm{~m}$, em delineamento experimental em blocos varietais casualizados, com 10 plantas por genótipo, perfazendo-se quatro linhas com duas cultivares por linha. O sistema de condução adotado foi o de dupla espaldeira em "t", com arames a $90 \mathrm{~cm}$ de altura, e as plantas foram manejadas e mantidas sob sistema agroecológico, sem aplicação de adubação química ou agrotóxicos. Foram realizadas adubações anuais com esterco bovino curtido, na proporção de $3 \mathrm{~kg} \mathrm{pl}^{-1}$, e durante o período de dormência das plantas foi realizado tratamento de inverno à base de calda sulfocálcica. Para análise das características dos frutos, a média de cada ano (três) foi considerada como repetição. Essa coleção foi mantida sob manejo agroecológico sem a aplicação de insumos sintéticos.

As avaliações fenológicas foram realizadas de acordo com a descrição dos estádios de desenvolvimento de gema (ANTUNES et al., 2000), sendo observadas as datas de início da floração (mais de 5\% das flores abertas), fim da floração (90\% das flores abertas), início e final da colheita.

Os frutos foram colhidos a partir do mês de novembro, separadamente de cada genótipo, quando estavam no estágio de maturação completa, com coloração negra, em cestas plásticas de colheita, com

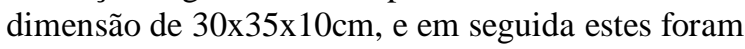
levados ao Laboratório de Melhoramento Genético da Embrapa Clima Temperado, sendo realizadas as avaliações de número de frutos, massa fresca de fruto (g) e teor de sólidos solúveis totais ( ${ }^{\circ}$ Brix), com auxílio de refratômetro digital de bancada. A produção média estimada por planta $\left(\mathrm{g} \mathrm{pl}^{-1}\right)$ foi obtida com a massa da matéria fresca de cada fruto multiplicada pelo número de frutos por planta. A produtividade $\left(\mathrm{kg} \mathrm{ha}^{-1}\right)$ foi baseada na densidade de 4.081 plantas por ha (com espaçamento de $3,5 \mathrm{~m}$ entre linhas e $0,7 \mathrm{~m}$ entre plantas), sendo obtida pela multiplicação do peso médio por planta e densidade (plantas por ha).

Os dados das variáveis analisadas foram submetidos à análise da variância, sendo posteriormente comparadas pelo teste de Scott \& Knott, a 5\% de significância, por meio do programa estatístico SISVAR (FERREIRA, 2000).

\section{RESULTADOS E DISCUSSÃO}

O período de florescimento teve início no mês de setembro (ciclos 2003/04 e 2004/05), e o ciclo 2005/06 ocorreu na segunda quinzena de agosto e no início de setembro, com exceção de 'Brazos', considerada uma das mais precoces (ANTUNES et al., 2000), cujo florescimento ocorreu no início de agosto. No ciclo 2003/04, o final de floração ocorreu no início do mês de novembro e para todas as cultivares. No segundo ciclo avaliado (2004/05), o final da floração ocorreu na segunda quinzena de setembro para duas cultivares e uma das seleções (787). Entretanto, no último ciclo de avaliação (2005/06), para 'Brazos', o florescimento findou na primeira quinzena de novembro e, para as demais cultivares, na segunda quinzena daquele mês (Tabela 1), o que pode ser devido a fenômenos climáticos, como o excesso de chuvas ocorrido durante o mês de outubro de 2005, com quase três vezes a mesma média dos anos anteriores (Tabela 2). 
Tabela 1 - Características fenológicas de sete cultivares de amoreira-preta em três ciclos produtivos (2003/04, 2004/05 e 2005/06).

\begin{tabular}{|c|c|c|c|c|c|}
\hline \multirow{3}{*}{ Cultivar } & \multicolumn{2}{|c|}{-----------Floração------------ } & \multicolumn{2}{|c|}{----------Colheita----------- } & \multirow{3}{*}{ Período de colheita (Dias) } \\
\hline & & & & & \\
\hline & Início & Final & Início & Final & \\
\hline & \multicolumn{5}{|c|}{ - } \\
\hline ‘Tupy’ & $20 / 09$ & $1 / 11$ & $02 / 12$ & $02 / 01$ & 30 \\
\hline 'Guarani' & $10 / 09$ & $1 / 11$ & $03 / 12$ & $19 / 01$ & 46 \\
\hline 'Caingangue' & $16 / 09$ & $1 / 11$ & $03 / 12$ & $21 / 01$ & 48 \\
\hline 'Cherokee' & $20 / 09$ & $1 / 11$ & $03 / 12$ & $21 / 01$ & 48 \\
\hline 'Brazos' & $10 / 09$ & $1 / 11$ & $15 / 11$ & $13 / 01$ & 60 \\
\hline 'Seleção 97' & $25 / 09$ & $1 / 11$ & $03 / 12$ & $31 / 01$ & 58 \\
\hline 'Seleção 787' & - & - & $18 / 11$ & $22 / 01$ & 64 \\
\hline 'Tupy' & $02 / 09$ & - & $08 / 11$ & $11 / 01$ & 64 \\
\hline 'Guarani' & $20 / 08$ & $21 / 10$ & $08 / 11$ & $11 / 01$ & 64 \\
\hline 'Caingangue' & $22 / 09$ & $08 / 11$ & $08 / 11$ & $11 / 01$ & 64 \\
\hline 'Cherokee' & $02 / 09$ & - & $08 / 11$ & $11 / 01$ & 64 \\
\hline 'Brazos' & $10 / 08$ & $21 / 10$ & $08 / 11$ & $21 / 12$ & 43 \\
\hline 'Seleção 97' & $28 / 09$ & - & $08 / 11$ & $11 / 01$ & 64 \\
\hline 'Seleção 787' & $22 / 09$ & $21 / 10$ & $08 / 11$ & $11 / 01$ & 64 \\
\hline ‘Tupy’ & $17 / 08$ & $15 / 11$ & ------2 & $23 / 01$ & 63 \\
\hline 'Guarani' & $17 / 08$ & $15 / 11$ & $22 / 11$ & $30 / 01$ & 68 \\
\hline 'Caingangue' & $17 / 08$ & $15 / 11$ & $22 / 11$ & $23 / 01$ & 61 \\
\hline 'Cherokee' & $17 / 08$ & $15 / 11$ & $17 / 11$ & $23 / 01$ & 65 \\
\hline 'Brazos' & $10 / 08$ & $04 / 11$ & $11 / 11$ & $09 / 01$ & 58 \\
\hline 'Seleção 97' & $5 / 09$ & $15 / 11$ & $17 / 11$ & $30 / 01$ & 74 \\
\hline 'Seleção 787' & $5 / 09$ & $15 / 11$ & $17 / 11$ & $30 / 01$ & 74 \\
\hline
\end{tabular}

Essa variação no padrão fenológico é função da característica genética de cada cultivar e de fenômenos climáticos, como temperatura e fotoperíodo, que interferem na floração e brotação. Além disso, o próprio sistema de produção adotado pode alterar características intrínsecas da cultivar trabalhada, como observado por SWAIN \& DARNELL (2002), e modifica o padrão produtivo e fisiológico da planta. Também a forma de condução das plantas jovens (WILLIANSON \& NESMITH, 2007), se não realizada corretamente, resulta na formação de plantas debilitadas e com baixa produção. Nesse sentido, BROETTO et al. (2009) verificaram atraso no período de floração em 'Xavante' manejada sob poda curta.
Segundo RASEIRA et al. (1992), a cultivar 'Caingangue', em Pelotas (RS), tem plena floração na primeira dezena de outubro e período de produção da segunda dezena de novembro até a segunda dezena de dezembro.

Essa alteração no padrão de florescimento deve-se a variações anuais no acúmulo em horas de frio, oscilações de temperatura ocorridas entre os meses de maio a setembro nos anos avaliados (Tabela 3) e exigências em frio de cada cultivar (CHILDERS \& LYRENE, 2006). Resultados semelhantes foram obtidos em outras regiões de cultivo, como citado por PERUZZO et al. (1995), em Santa Catarina, eANTUNES et al. (2000), no Sul de Minas Gerais.

Tabela 2 - Precipitação (milímetros) nos meses de janeiro a dezembro dos anos de 2003 a 2006, na Estação Experimental de Cascata da Embrapa Clima Temperado.

\begin{tabular}{lllllllllllll}
\hline Anos & Jan & Fev & Mar & Abr & Mai & Jun & Jul & Ago & Set & Out & Nov & Dez \\
\hline 2003 & 13,7 & 194,3 & 90,7 & 120,6 & 67,4 & 224,1 & 113,7 & 53,3 & 132,7 & 52,0 & 119,9 & 89,7 \\
2004 & 69,9 & 50,6 & 28,4 & 137,9 & 459,1 & 68,1 & 70,1 & 98,6 & 114,0 & 47,3 & 116,5 & 43,0 \\
2005 & 44,1 & 54,5 & 70,5 & 122,8 & 113,7 & 54,1 & 37,4 & 119,3 & 189,0 & 157,2 & 5,4 & 8,1 \\
2006 & 87,8 & 124,8 & 161,5 & 29,3 & 94,7 & 119,7 & 113,1 & 131,3 & 105,9 & 64,1 & 164,2 & 106,9 \\
\hline
\end{tabular}

Ciência Rural, v.40, n.9, set, 2010. 
Tabela 3 - Acúmulo de horas de frio* (abaixo de $7,2^{\circ} \mathrm{C}$ ) e média das temperaturas $\left({ }^{\circ} \mathrm{C}\right)$ máximas e mínimas nos meses de maio a setembro dos anos de 2002 a 2006, na Estação Experimental de Cascata da Embrapa Clima Temperado.

\begin{tabular}{cccc}
\hline Ano & Horas de frio & $\begin{array}{c}\text { Temperatura } \\
\text { máxima }\end{array}$ & $\begin{array}{c}\text { Temperatura } \\
\text { mínima }\end{array}$ \\
\hline 2002 & 380 & 19 & 10 \\
2003 & 426 & 19 & 13 \\
2004 & 441 & 20 & 9 \\
2005 & 276 & 20 & 10 \\
2006 & 474 & 19 & 9 \\
\hline
\end{tabular}

*Segundo metodologia descrita por REISSER JUNIOR et al. (2005).

Na média dos três anos de avaliações, o período de colheita estendeu-se por 57 dias, entre os meses de novembro e janeiro, e o menor período de colheita ocorreu no primeiro ciclo de avaliação, com 30 dias para 'Tupy', e o maior período obtido no terceiro ciclo (74 dias), para seleções 97 e 787 (Tabela 1). Esses valores estão dentro dos intervalos encontrados por ANTUNES et al. (2000) e ANTUNES et al. (2006), respectivamente, para produção de safra e extemporânea no Sul de Minas Gerais.

ANTUNES et al. (2000) verificaram que o período de colheita de amora-preta, em manejo convencional nas condições do Sul de Minas Gerais, estendeu-se de outubro a fevereiro, e a cultivar 'Brazos' foi a mais produtiva $\left(5,3 \mathrm{~kg} \mathrm{pl}^{-1}\right)$, com início de produção a partir da $3^{\text {a }}$ dezena de outubro, seguida de 'Guarani' $\left(4,7 \mathrm{~kg} \mathrm{pl}^{-1}\right)$, 'Tupy' $\left(3,6 \mathrm{~kg} \mathrm{pl}^{-1}\right) \mathrm{e}$ 'Comanche' $\left(3,4 \mathrm{~kg} \mathrm{pl}^{-1}\right)$, sendo a menos produtiva a 'seleção 97 ' $\left(\mathrm{kg} \mathrm{pl}^{-1}\right)$. Já BROETTO et al. (2009) estudando o cultivo orgânico de amoreira-preta, obtiveram produtividade de $3.026 \mathrm{~kg}$ ha $^{-1}$, em Guarapuava (PR), para a cultivar 'Xavante', enquanto BOTELHO et al. (2009), no mesmo município e com a mesma cultivar, obtiveram $5.952 \mathrm{~kg} \mathrm{ha}^{-1} \mathrm{em}$ sistema convencional.

Em relação às características físicas da produção (Tabela 4), embora não significativas ao teste estatístico aplicado, as maiores produções foram obtidos pela 'seleção 787 ' $\left(1.355 \mathrm{~g} \mathrm{pl}^{-1}\right)$ e pelas cultivares 'Caingangue' $\left(1.305 \mathrm{~g} \mathrm{pl}^{-1}\right) \mathrm{e}$ 'Tupy' $\left(1.149 \mathrm{~g} \mathrm{pl}^{-1}\right)$. Por outro lado, as menores produções foram obtidas pela 'seleção 97' (589. $\left.\mathrm{g} \mathrm{l}^{-1}\right)$ e pela cultivar 'Brazos' $\left(621 \mathrm{~g} \mathrm{pl}^{-1}\right)$. Essa produção pode ser extrapolada para o potencial de produtividade, que coloca a 'seleção 787 ' $(4.358 \mathrm{~kg}$ $\left.\mathrm{ha}^{-1}\right) \mathrm{e}$ as cultivares 'Caingangue' $\left(5.869 \mathrm{~kg} \mathrm{ha}^{-1}\right) \mathrm{e}^{\text {'Tupy' }}$ $\left(5.169 \mathrm{~kg} \mathrm{ha}^{-1}\right)$ como as de maior potencial de exploração na região de Pelotas sob regime de produção agroecológica. A diferença apresentada pelas cultivares e seleções, embora não significativa, pode ser devido a fatores intrínsecos relacionados à própria adaptação, como a exigência em frio e as variações climáticas locais (Tabela 3) ou ainda pela densidade de plantio empregada (RASEIRA et al., 2007).

As médias de massa fresca dos frutos entre as cultivares diferiram estatisticamente, mesmo com a não variação ocorrida nos índices de produção, que poderiam colaborar para alteração da relação fonte e dreno, ou seja, em cultivares com menor produção, os frutos poderiam apresentar maior tamanho e massa de matéria fresca (Tabela 4). As maiores massas de frutos foram obtidas para 'seleção 787' (5,14g), 'seleção 97' $(4,94 \mathrm{~g})$, 'Brazos' $(4,8 \mathrm{~g})$, 'Tupy' $(4,18)$ e 'Caingangue' (3,9g) (Tabela 4). ANTUNES et al. (2000) e ANTUNES et al. (2006), avaliando sete cultivares e uma seleção de amoreira-preta, em quatro ciclos de produção, observaram diferenças significativas entre as massas dos frutos obtidos, que, de uma forma geral, foram

Tabela 4 - Produção, produtividade, número e massa da matéria fresca de frutos (MMF) e teor de sólidos solúveis totais (SST) de frutos de sete cultivares de amoreira-preta produzidos em Pelotas, $\mathrm{RS}^{(1)}$.

\begin{tabular}{lccccc}
\hline Cultivares & Produção $\left(\mathrm{g} \mathrm{pl}^{-1}\right)$ & Produtividade $\left(\mathrm{kg} \mathrm{ha}^{-1}\right)$ & Número de frutos & MFF $(\mathrm{g})$ & SST $\left({ }^{\circ}\right.$ Brix $)$ \\
\hline 'Tupy' & $1.149^{\mathrm{ns}}$ & $5.169^{\text {ns }}$ & $2.878^{\text {ns }}$ & $4,18 \mathrm{a}$ & $8,68^{\mathrm{ns}}$ \\
'Guarani' & 917 & 4.915 & 3.018 & $2,83 \mathrm{~b}$ & 9,90 \\
'Caingangue' & 1.305 & 5.869 & 2.814 & $3,90 \mathrm{a}$ & 8,99 \\
'Cherokee' & 957 & 4.305 & 3.283 & $3,04 \mathrm{~b}$ & 9,36 \\
'Brazos' & 621 & 2.794 & 1.680 & $4,80 \mathrm{a}$ & 9,87 \\
'Seleção 97' & 589 & 2.649 & 1.422 & $4,94 \mathrm{a}$ & 9,89 \\
'Seleção 787' & 1.355 & 4.358 & 2.703 & $5,14 \mathrm{a}$ & 9,45 \\
Média & 984 & 4.295 & 2.543 & 4,11 & 9,45 \\
CV (\%) & 54,3 & 60,5 & 65,4 & 19,1 & 13,1 \\
\hline
\end{tabular}

${ }^{(1)}$ Cálculo considerando espaçamento $(3,5 \mathrm{mx} 0,7 \mathrm{~m})$ com a densidade de 4.081 plantas ha ${ }^{-1}$.

Médias seguidas pela mesma letra não diferem entre si, nas colunas, pelo teste de Scott \& Knott, a $5 \%$ de probabilidade. ${ }^{\text {NS }}$ - não significativo a $5 \%$ de probabilidade. 
superiores aos valores obtidos neste trabalho. Quanto ao teor de sólidos solúveis totais (Tabela 4), não houve diferenças significativas entre as cultivares avaliadas, sendo a média de $9,45^{\circ}$ Brix.

\section{CONCLUSÃO}

Na região de Pelotas, RS, recomenda-se o cultivo agroecológico das cultivares de amoreira-preta 'Tupy', 'Guarani', 'Caingangue', 'Cherokee', 'Brazos' e das seleções 97 e 787. Maior massa fresca de frutos foi observada nas cultivares 'Tupy', 'Caingangue', 'Brazos' e na 'seleção 97' e na 'seleção 787'. Não há diferenças entre as cultivares para produção, produtividade, número de frutos e teores de sólidos solúveis totais.

\section{AGRADECIMENTOS}

Os autores agradecem à Fundação de Amparo à Pesquisa do Estado do Rio Grande do Sul, pelo apoio financeiro; e ao Conselho Nacional de Desenvolvimento Científico e Tecnológico, pela concessão do auxílio financeiro e de bolsas de pesquisa.

\section{REFERÊNCIAS}

ANTUNES, L.E.C. Amora-preta: nova opção de cultivo no Brasil. Ciência Rural, Santa Maria, v.32, n.1, p.151-158, 2002. Disponível em: <http://www.scielo.br/scielo.php?script=sci_arttext\&pid=S010384782002000100026\&lng=pt\&nrm=iso $>$. Acesso em: 01 fev. 2006.

ANTUNES, L.E.C. et al. Blossom and ripening periods of blackberry varieties in Brazil. Journal American Pomological Society, Massachusetts, v.54, n.4, p.164-168, 2000 .

ANTUNES, L.E.C.; RASEIRA, M.C.B. Cultivo de amoreirapreta (Rubus spp). Pelotas: Embrapa Clima Temperado. 2007. 130p. (Embrapa Clima Temperado. Sistema de Produção, 12).

ANTUNES, L.E.C. et al. Produção extemporânea de amorapreta. Revista Brasileira de Fruticultura, Jaboticabal, v.28, n.3, p.430-434, 2006. Disponível em: <http://www.scielo.br/ scielo.php? script=sci_arttext \& pid=S $0100-$ $29452006000300020 \& \operatorname{lng}=$ pt\&nrm=iso>. Acesso em: $10 \mathrm{fev}$. 2007.

AQUINO, A.M.; ASSIS, R.L. de. Agricultura orgânica em áreas urbanas e periurbanas com base na agroecologia. Ambiente \& Sociedade, Campinas, v.10, n.1, p.137-150, 2007. Disponível em: <http://www.scielo.br/ scielo.php? script=sci_arttext \& pid=S $1414-$ $753 \times 2007000100009 \& \operatorname{lng}=$ pt\&nrm=iso $>$. Acesso em: 27 jun. 2010.
ATTILIO, L.B. et al. Custo de produção de amora-preta em região tropical. Revista Brasileira de Fruticultura, Jaboticabal, v.31, n.4, p.1042-1047, 2009. <Disponível em: http://www.scielo.br/scielo.php?script=sci_arttext\&pid=S0100$29452009000400017 \& \operatorname{lng}=$ pt\&nrm=iso $>$. Acesso em: 26 jun. 2010.

BROETTO, D. et al. Cultivo orgânico de amora-preta cv Xavante em Guarapuava-PR. Revista Brasileira de Agroecologia, Cruz Alta, v.4, n.2, p.2208-2212, 2009.

BOTELHO, R.V. et al. Fenologia e produção da amoreirapreta sem espinho cv Xavante na região de Guarapuava-PR. Scientia Agrária, Curitiba, v.10, n.3, p.209-214, 2009.

CHILDERS, N.F.; LYRENE, P.M. Blueberries for growers, gardeners, promoters. Florida: Painter Printing, 2006. 266 p.

CLARK, J.R. World production and perspectives. In: SIMPÓSIO NACIONAL DO MORANGO, 3.; ENCONTRO DE PEQUENAS FRUTAS E FRUTAS NATIVAS DO MERCOSUL, 2., 2006, Pelotas, RS. Palestras... Pelotas: Embrapa Clima Temperado, 2006. p.11-16. (Embrapa Clima Temperado. Documentos, 171).

FERREIRA, D.F. Análises estatísticas por meio do Sisvar para Windows versão 4. 0. In: REUNIÃO ANUAL DA REGIÃO BRASILEIRA DA SOCIEDADE INTERNACIONAL DE BIOMETRIA, 45., 2000, São Carlos, SP. Anais... São Carlos: UFSCar, 2000. p.255-258.

PERUZZO, E.L. et al. Amora-preta: variedades e propagação. Agropecuária Catarinense, Florianópolis, v.8, n.3, p.53$55,1995$.

RASEIRA, A. et al. Influência da densidade de plantio na produtividade de cultivares de amoreira-preta. Revista Brasileira de Agrociências, Pelotas, v.13, n.4, p.551-554, 2007.

RASEIRA, A. e $\mathrm{t}$ al. Caingangue, nova cultivar de amora-preta para consumo 'in natura'. Horti Sul, Pelotas, v.2, n.3, p.11$12,1992$.

REISSER JUNIOR, C. et al. Correlação do acúmulo de horas de frio entre duas estações agroclimatológicas situadas em diferentes posições geográficas no município de Pelotas-RS. Pelotas: Embrapa Clima Temperado, 2005. 3p. (Comunicado técnico, n. 110).

STRIK, B. C. et al. Worldwide blackberry production. Hortechnology, Alexandria, v.17, n.2, p.205-213, 2007.

SWAIN, P.A.W.; DARNELL, R.L. Production systems influence source limitations to growth in 'Sharpblue' southern highbush blueberry. Journal American Society for Horticultural Science, Alexandria, v.127, n.3, p.409-414, 2002.

WILLIANSON, J.G.; NESMITH, D.S. Evaluation of flower bud removal treatment on growth of young blueberry plants. Hortscience, Alexandria, v.42, n.3, p.571-573, 2007. 